\title{
Study on Dispersion of Cement Grout in Sand considering Filtration Effect through the EDTA Titration Test
}

\author{
Daimao Li, ${ }^{1}$ Xuhui Li, ${ }^{1}$ Yu Hu, ${ }^{2}$ Sizhan Zhang, ${ }^{3}$ Chao Mei, ${ }^{2}$ Hao Wu, ${ }^{2}$ Xiaohui Sun (D, ${ }^{2}$ \\ and Yanbin $\mathrm{Fu}^{2,4}$ \\ ${ }^{1}$ Guangdong GDH Pearl River Delta Water Supply Co. Ltd., Guangzhou 511458, China \\ ${ }^{2}$ College of Civil and Transportation Engineering, Shenzhen University, Shenzhen 518060, China \\ ${ }^{3}$ Hongrongyuan Enterprise Development (Group) Co. Ltd., 99 Xinhu Rd., Baoan District, Shenzhen 518060, China \\ ${ }^{4}$ Key Laboratory of Coastal Urban Resilient Infrastructures (MOE), Shenzhen University, Shenzhen 518060, China
}

Correspondence should be addressed to Xiaohui Sun; sunxiaohui@szu.edu.cn

Received 14 November 2020; Revised 8 December 2020; Accepted 17 December 2020; Published 31 December 2020

Academic Editor: Zhigang Tao

Copyright (c) 2020 Daimao Li et al. This is an open access article distributed under the Creative Commons Attribution License, which permits unrestricted use, distribution, and reproduction in any medium, provided the original work is properly cited.

When grouting in a sand layer, the filtration of the layer on cement particles is an important aspect affecting the grout dispersion. However, few laboratory studies have been conducted to investigate the distribution of cement particles along the direction of dispersion. In this study, a group of laboratory tests were conducted by grouting in a sand layer under different levels of pressure. The distributions of cement particles in sand after curing were then measured using the EDTA titration test. The results show that, due to the filtration effect, the cement content along the radial direction of dispersion decreases nonlinearly in a reversed $S$ shape. The filtration effect becomes more obvious when grouting with a higher grout concentration. With the decrease in grout concentration, the filtration effect becomes weak and cement particles could disperse farther in the sand layer, but the cement content in a farther location becomes lower and the improvement of the soil strength is limited. In the end, the measured results were compared with the calculated results according to an existing theoretical study and the trend reasonably matches with each other.

\section{Introduction}

Grouting is a widely used technique in geotechnical applications, including for antiseepage, leak stopping, and ground improvement. For example, grouting technology is widely used in slope reinforcement [1]. In the engineering practice, cement grout is the most common grouting material. Due to the existence of voids in soil layers, the grout disperses through the voids during injection [2] and some cement particles are evidently blocked by the skeleton of soil particles. In other words, the soil layer serves as a filter to retain the cement particles and this phenomenon is so called the filtration effect $[3,4]$, as shown in Figure 1. In the process of grouting, the permeability of soil decreases gradually and the dispersion of cement grout would slow down and stop eventually. The filtration effect is significantly influenced by grouting pressure, distance of grouting dispersion, concentration of the grout, etc.

Experimental studies have been conducted in previous studies to investigate the filtration effect in permeation grouting. Bezuijen et al. [5] carried out grouting tests in fine sand and confirmed the existence of the filtration effect in the grouting process. Bolton and McKinley [6] performed grouting tests with different cement grouts under various pressures to understand the influence of the filtration effect on the porosity and permeability of cemented mass. Eriksson et al. [7] predicted the movement and distribution of cement particles by numerical analysis based on a network model of slurry dispersion and evaluated the improvement of ground by grouting. Saada et al. [4] carried out a one-dimensional grouting laboratory test using a custom-made test device and developed a theoretical solution for the suspension 


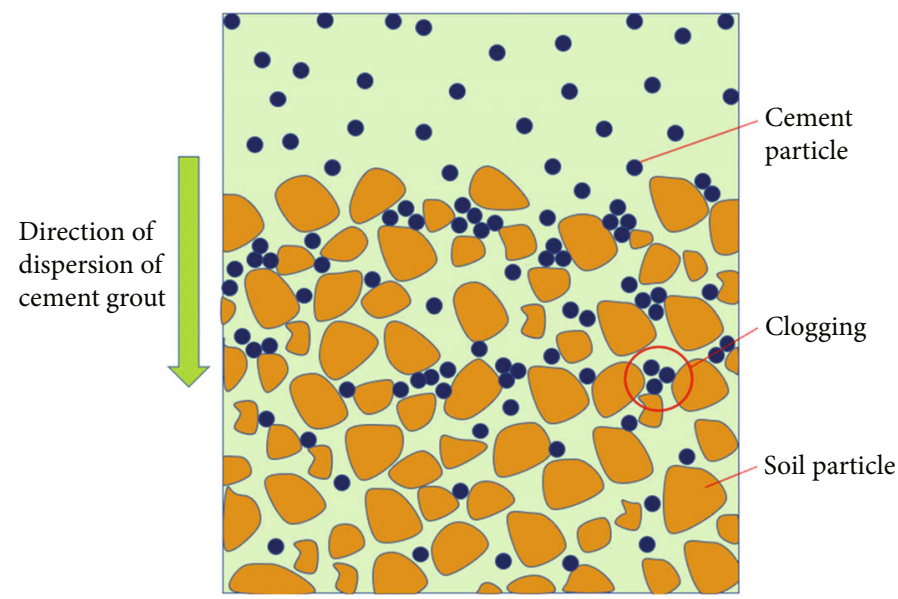

Figure 1: Schematic diagram of the filtration effect.

permeation of cement particles in porous media considering the filtration effect. Yoon and Mohtar [8] carried out an experimental study on the groutability of the modified bentonite slurry considering the influence of the particle size and $\mathrm{pH}$ value of the slurry on the filtration effect and proposed a new guideline for determining the groutability of the bentonite slurry.

Researchers also investigated the influencing factors of the filtration effect using on theoretical analysis. Maghous et al. [9] developed a numerical solution for cylindrical permeation grouting in porous media based on the theoretical model proposed by Saada et al. [4]. Chupin et al. [10] investigated the influencing factors of Saada's theoretical solution using the one-dimensional grouting test. Kim et al. [11] and Zhou et al. [12] proposed the filtration characteristics of grout in porous media mathematically and developed a method for calculating the reduction of soil porosity caused by grouting. Zhou et al. [13] investigated the radial distribution of the cement concentration under the filtration effect in the improvement of a pile foundation through grouting. Yang et al. [14] simulated the grouting process by coupling the filtration effect with the erosion effect.

However, the experimental study for investigating the spatial distribution of cement particles in the soil layer is relatively rare and the distribution of cement particles could influence the strength of the grouted layer directly. Therefore, a series of grouting tests in a sand layer and the Ethylenediaminetetraacetic Acid (EDTA) titration tests using grouted sand samples were conducted to investigate the distribution of the cement particles along the direction of dispersion. The test results of this study were subsequently used to verify the effectiveness of an existing theoretical equation.

\section{Test Materials and Test Method}

\subsection{Grouting Test}

2.1.1. Test Materials. The injectability of soil is an important factor affecting the filtration effect. When the cracks or voids in soil are much larger than the cement particles in the grout, the grout can be easily injected and the filtration effect is not significant [15]. If the size of the cement particle in the grout is larger than that of the voids in soil, the grout cannot be injected into the soil. When the size of the grout particles is close to but smaller than that of the voids in soil, the soil skeleton will act as a filter, resulting in the retention of grout particles in the voids. Therefore, the ratio of the soil particle size to that of grout grouting materials affects the injectability of soil. The commonly used criterion is as follows [2]:

$$
\begin{gathered}
\frac{D_{15}}{d_{85}} \geq 15, \\
\frac{D_{10}}{d_{95}} \geq 8,
\end{gathered}
$$

where $D_{10}$ and $D_{15}$ are the diameters of soil particles corresponding to $10 \%$ and $15 \%$ finer, respectively. $d_{85}$ and $d_{95}$ are the corresponding diameters of $85 \%$ and $95 \%$ finer of grouting materials, respectively.

Based on the criterion as shown in Equation (1), the test materials were selected. P.I 42.5 ordinary Portland cement produced by Henan Zhuonenda Construction Materials Co., Ltd. was selected as the cement used in this study. The sand layer was filled in the test box layer by layer (the thickness of the layer is $5 \mathrm{~cm}$ ), with a moisture content of $5 \%$, moist density of $2.65 \mathrm{~g} / \mathrm{cm}^{3}$, porosity of 0.42 , and permeability of $0.344 \mathrm{~m} / \mathrm{s}$. Figure 2 shows the grading curves of cement and sand used in this study.

As shown in Figure 2, for the sand used in this study, $D_{10}=0.20 \mathrm{~mm}$ and $D_{15}=0.14 \mathrm{~mm}$, while for the cement used in this study, $d_{85}$ and $d_{95}$ equals $0.0095 \mathrm{~mm}$ and $0.021 \mathrm{~mm}$, respectively. According to Equation (1), $D_{15} / d_{85} \approx 15$ and $D_{10} / d_{95} \approx 9.5$. Therefore, the cement grout is injectable in this sand layer and the filtration effect would occur during grouting [16].

(1) Grouting Test Device. Figure 3 shows the test set-up used for the grouting test in this study. The device is composed of a test box, a grouting system, a compressor, and a measuring system as shown in the figure. During the test, the grout was pumped with constant pressure into the sand, which was 


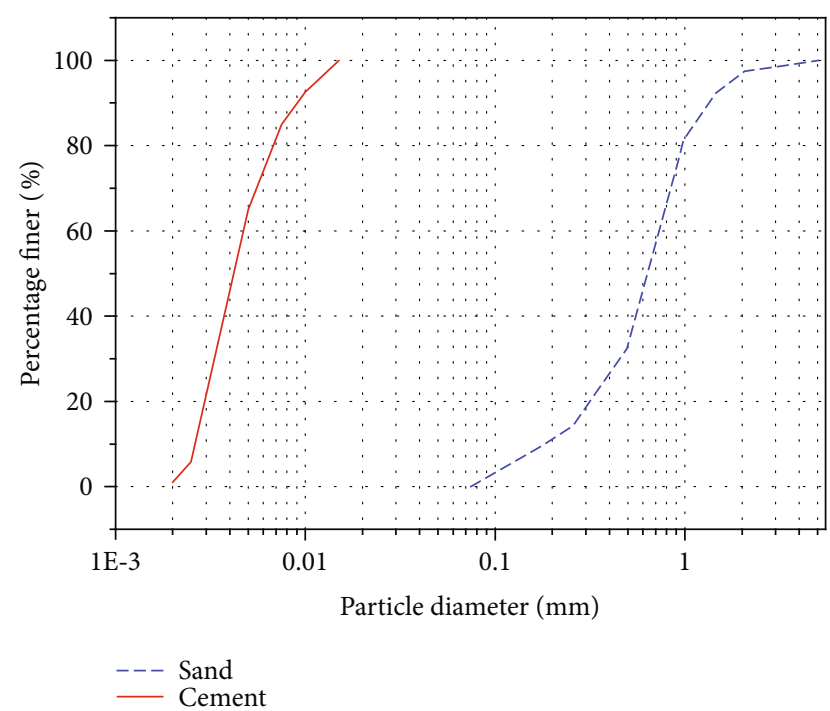

FIGURE 2: The gradation of cement and sand used in this study.

constructed layer by layer in the test box, and the whole process was monitored. The flowmeter was used to record the volume of the grout injected into the sand layer. The electronic balance underneath the grout tank was used to measure the weight difference before and after grouting, so as to determine the amount of the cement grout injected. The injection was stopped when the amount of cement grout did not change.

2.1.2. Test Plan. In order to study the spatial distribution of cement particles in the sand layer under the filtration effect, three kinds of cement grouts with a water-cement ratio of $0.8,1.0$, and 1.2 were used in the grouting tests under three different pressures. The corresponding volumetric content of cement particles in the grout is $0.294,0.250$, and 0.217, respectively, according to the following equation:

$$
\omega=\frac{\rho_{\mathrm{w}}}{\rho_{\mathrm{w}}+(W / C) \rho_{\mathrm{c}}},
$$

where $\omega$ is the volumetric content of cement particles in the grout.

Table 1 shows the grouting test plan.

2.2. Test of Cement Content along the Radius of the Cemented Mass. The distribution of cement particles along the radius of the cemented mass was quantitatively analyzed using the EDTA sodium titration method. For the EDTA test, samples were taken at the positions of $0,0.2,0.4,0.6,0.8$, and 1 time of the radius of the cured cemented mass. Figure 4 shows the cemented mass and the samples cut from the mass used for the EDTA test.

2.2.1. EDTA Disodium Titration Apparatus and Process. In the test, the sample of the cemented mass was dried in an oven first and then grinded into fines in a mold. The grinded fines were then put into a beaker for titration. Firstly, the $\mathrm{Ca}^{2+}$ in a grinded fine sample was extracted by adding a weak acid solution, $\mathrm{NH}_{4} \mathrm{Cl}$, into the beaker. Then, the $\mathrm{pH}$ value of the solution was adjusted to $12.5-13.0$ by adding $\mathrm{NaOH}$ solution so as to eliminate the interference of other ions during titration, such as $\mathrm{Mg}^{2+}, \mathrm{Fe}^{3+}, \mathrm{Al}^{3+}$, and $\mathrm{Mn}^{2+}$. A small amount of a calcium red indicator was added to the extracted solution to form a red complex with $\mathrm{Ca}^{2+}$. The extracted solution was then titrated with the EDTA disodium standard solution until the color turned from red to light blue.

To obtain the cement content of the grouted mass by the titration test, the correlation between the consumption of disodium EDTA and the cement content should be obtained first. Seven samples with the cement content (by weight) of $5 \%, 10 \%, 15 \%, 20 \%, 25 \%, 30 \%$, and $35 \%$ were prepared and used for the titration test. Figure 5 shows the consumption of the EDTA disodium solution of the samples with various cement contents. As shown in Figure 5, linear regression can be conducted to obtain a linear correlation between the cement content and the amount of the EDTA disodium consumption. During the test, the amount of the EDTA disodium standard solution consumed in titration was recorded and correlated with the cement content in the sample based on Equation (2).

\subsection{Test Results and Analysis}

2.3.1. Radius of Cemented Mass. Grouting was carried out according to the scheduled various cement grouts under different pressures. Table 2 shows the corresponding parameters measured or calculated for each test, including the radius of injector, $r_{0}$, the porosity of the sand layer, the filtration coefficient, the injection rate, and the radius of the cemented mass. It should be noted that the influencing factor of filtration coefficient $a$ is difficult to obtain by the theoretical method and was obtained by back-calculation based on a one-dimensional grouting test $[10,17,18]$.

2.3.2. Distribution of Cement Particles. Figures 6(a)-6(c) show the cement content by weight along the radius of the cemented sand mass under different injection pressures. As shown in the figure, in general, the distribution of cement particles along the direction of dispersion demonstrates a nonlinear reversed $\mathrm{S}$ shape. The reason for the phenomenon is that, due to the filtration effect, cement particles tend to be retained close to the grouting injector, resulting in a higher cement content in the center of the mass body. For a cement grout with a certain water-cement ratio, the dispersion distance (namely, the radius of the cemented sand mass) increased with the increase in the grout pressure. In other words, a higher grout pressure was able to carry the cement particles to a farther distance under the filtration effect.

On the other hand, under the same grout pressure, the radius of the cemented sand mass increased with the increase in the water-cement ratio of the grout. In other words, the cement particles tend to be clogged close to the injector for a grout with a low water-cement ratio and are easy to be moved to a farther distance when the grout has a higher water-cement ratio. In addition, a grout with a lower watercement ratio (a higher concentration) not only results in a smaller cemented sand mass but also leads to a higher decreasing rate of cement content along the radial direction. 


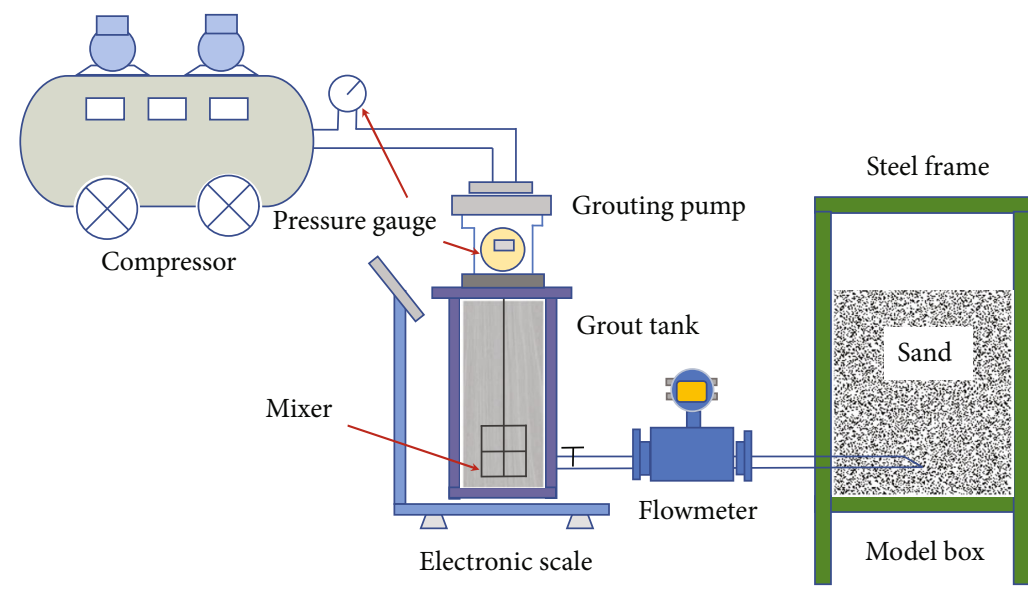

(a) Schematic diagram of the grouting test device

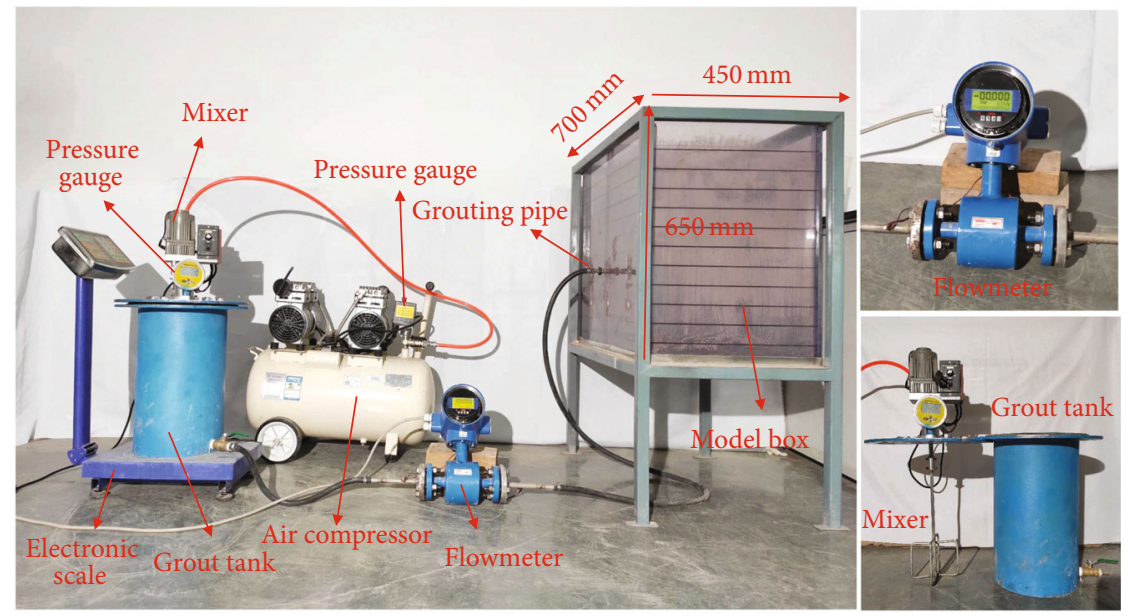

(b) Photos of the device

FIgURE 3: Test set-up.

TABLE 1: Test plan.

\begin{tabular}{lccc}
\hline $\begin{array}{l}\text { No. of } \\
\text { tests }\end{array}$ & $\begin{array}{c}\text { Volumetric content } \\
\omega(W / C)\end{array}$ & $\begin{array}{c}\text { Grouting } \\
\text { pressure }(\mathrm{kPa})\end{array}$ & $\begin{array}{c}\text { Porosity of } \\
\text { soil }\left(n_{0}\right)\end{array}$ \\
\hline 1 & & 180 & \\
2 & $0.294(0.8)$ & 200 & \\
3 & & 220 & \\
4 & & 180 & 0.42 \\
5 & $0.250(1.0)$ & 200 & \\
6 & & 220 & \\
7 & & 180 & \\
8 & $0.217(1.2)$ & 200 & \\
9 & & 220 & \\
\hline
\end{tabular}

The reason is that the retention of cement particles close to the injector enhanced the filtration effect and, as a result, led to the difficulty for cement particles to pass through the voids in sand clogged by cement particles. Another phenomenon worthy to be considered is that, even though the grout with a lower cement concentration could move farther under a certain grout pressure, the cement content at the edge of the cemented sand mass is generally lower, indicating the poor improvement in strength. It is usually considered that a cement content of $8 \%$ in soil is required for improving a sand layer. With this criterion, as shown in Figure 6, the test with a water-cement ratio of 1.0 had the highest ground improvement radius and that with a water-cement ratio of 0.8 had the lowest ground improvement radius. These results indicate that there is an optimum water-cement ratio for the grout during grouting in a certain layer and the watercement ratio should be chosen carefully in engineering practice.

2.4. Comparison of the Calculated and Experimental Results. According to Saada et al. [4], without considering the influence of time, the volume content of cement particles per unit volume can be expressed as

$$
\varphi_{\mathrm{c}}=\frac{n_{0}}{1+((1 / \omega)-1) \exp \left[\left(a / r_{0}^{2} V_{0}\right)\left(\left(r^{3}-r_{0}^{3}\right) / 3\right)\right]}\left(r_{0} \leq r \leq R\right) \text {, }
$$

where $n_{0}$ is the porosity before the slurry is injected into the soil and $a$ is the filtration coefficient. 


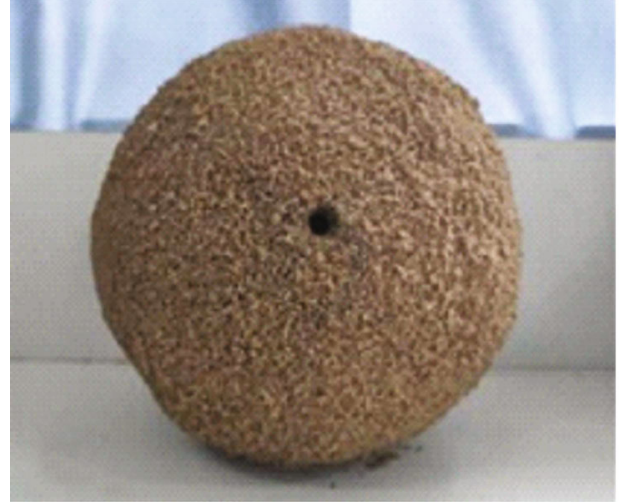

(a)

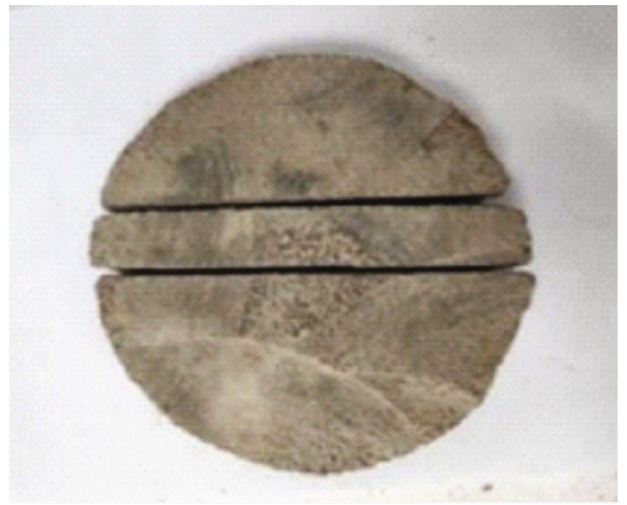

(c)

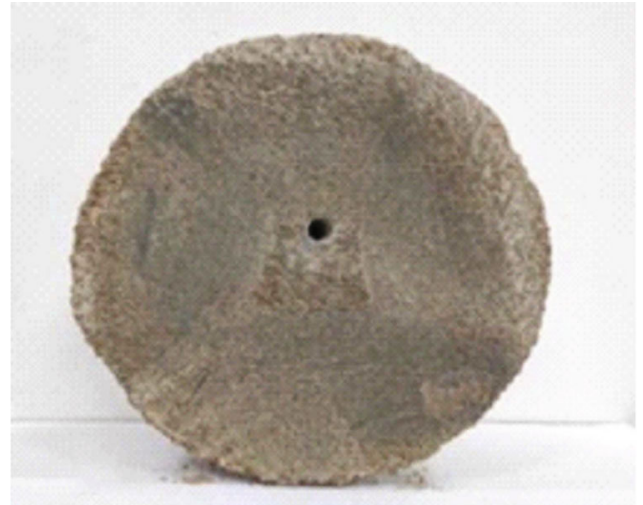

(b)

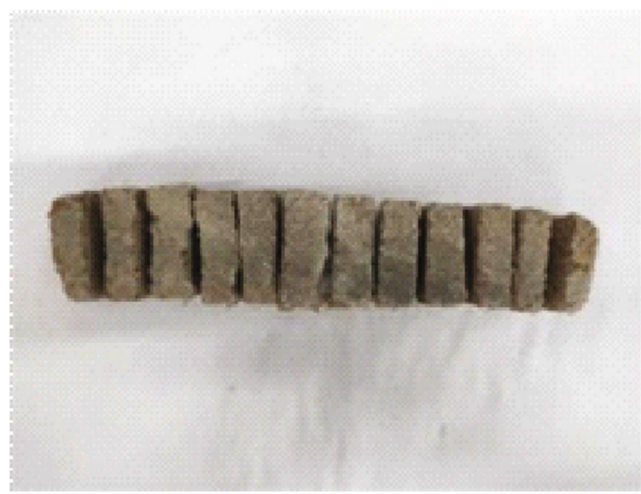

(d)

Figure 4: Samples prepared for the EDTA test: (a) cemented mass; (b) a thin pad cut from the cemented mass; (c) a strip cut from the thin pad; (d) samples made from the strip.

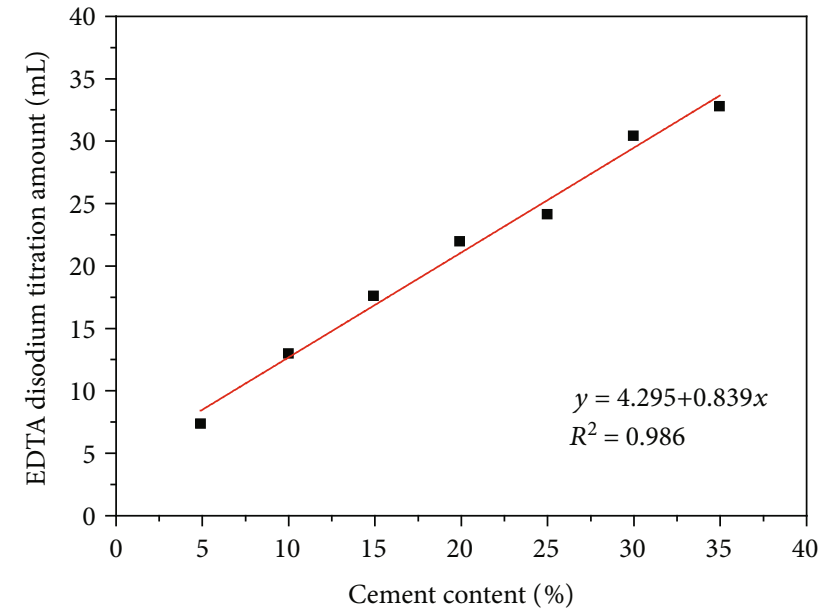

FIGURE 5: Correlation between disodium consumption of EDTA and cement content.

In Equation (3), $\varphi_{\mathrm{c}}$ is the volume content in the slurry diffusion area and can be expressed as

$$
\varphi_{\mathrm{c}}=\frac{V_{\mathrm{c}}}{V_{\mathrm{c}}+V_{\mathrm{w}}+V_{\mathrm{s}}},
$$

where $V_{c}$ is the volume of cement particles $\left(\mathrm{cm}^{3}\right), V_{\mathrm{w}}$ is the volume of water $\left(\mathrm{cm}^{3}\right)$, and $V_{\mathrm{s}}$ is the volume of sand $\left(\mathrm{cm}^{3}\right)$.

Assuming that the soil pore is completely filled with cement slurry, there are

$$
V_{\mathrm{c}}+V_{\mathrm{w}}=V_{\mathrm{a}} \text {, }
$$

where $V_{\mathrm{a}}$ is the pore volume of sand $\left(\mathrm{cm}^{3}\right)$.

The pore volume, particle volume, and porosity of soil have the following relationships:

$$
\frac{V_{\mathrm{a}}}{V_{\mathrm{s}}}=\frac{n_{0}}{1-n_{0}} .
$$

Substituting Equation (6) into Equation (5) yields

$$
V_{\mathrm{c}}+V_{\mathrm{w}}=\frac{n_{0} V_{\mathrm{s}}}{1-n_{0}}
$$

Substituting Equation (7) into Equation (4) and sorting out, one can obtain

$$
\varphi_{\mathrm{c}}=\frac{m_{\mathrm{c}} \rho_{\mathrm{s}}}{m_{\mathrm{s}} \rho_{\mathrm{c}}}\left(1-n_{0}\right) .
$$

After transforming Equation (8), the expression of 
TABLE 2: Grouting test results under each working condition.

\begin{tabular}{|c|c|c|c|c|c|c|}
\hline $\begin{array}{l}\text { Working } \\
\text { condition }\end{array}$ & $\begin{array}{l}\text { Grouting hole } \\
\text { radius } r_{0}(\mathrm{~m})\end{array}$ & $\begin{array}{l}\text { Porosity of } \\
\text { soil } n_{0} \\
\end{array}$ & $\begin{array}{c}\text { Cement volumetric } \\
\text { content } \omega\end{array}$ & $\begin{array}{c}\text { Filtration } \\
\text { coefficient } a\left(\mathrm{~s}^{-1}\right)\end{array}$ & $\begin{array}{c}\text { Injection rate } V_{0} \\
(\mathrm{~m} / \mathrm{s})\end{array}$ & $\begin{array}{c}\text { Radius of cemented } \\
\text { mass } R(\mathrm{~cm})\end{array}$ \\
\hline 1 & & & & & 0.0200 & 5.450 \\
\hline 2 & & & 0.294 & 0.0029 & 0.0331 & 7.545 \\
\hline 3 & & & & & 0.0452 & 8.440 \\
\hline 4 & & & & & 0.0241 & 8.655 \\
\hline 5 & 0.004 & 0.42 & 0.25 & 0.0024 & 0.0361 & 10.600 \\
\hline 6 & & & & & 0.0485 & 11.210 \\
\hline 7 & & & & & 0.0288 & 9.560 \\
\hline 8 & & & 0.217 & 0.0020 & 0.0395 & 11.473 \\
\hline 9 & & & & & 0.0531 & 13.085 \\
\hline
\end{tabular}
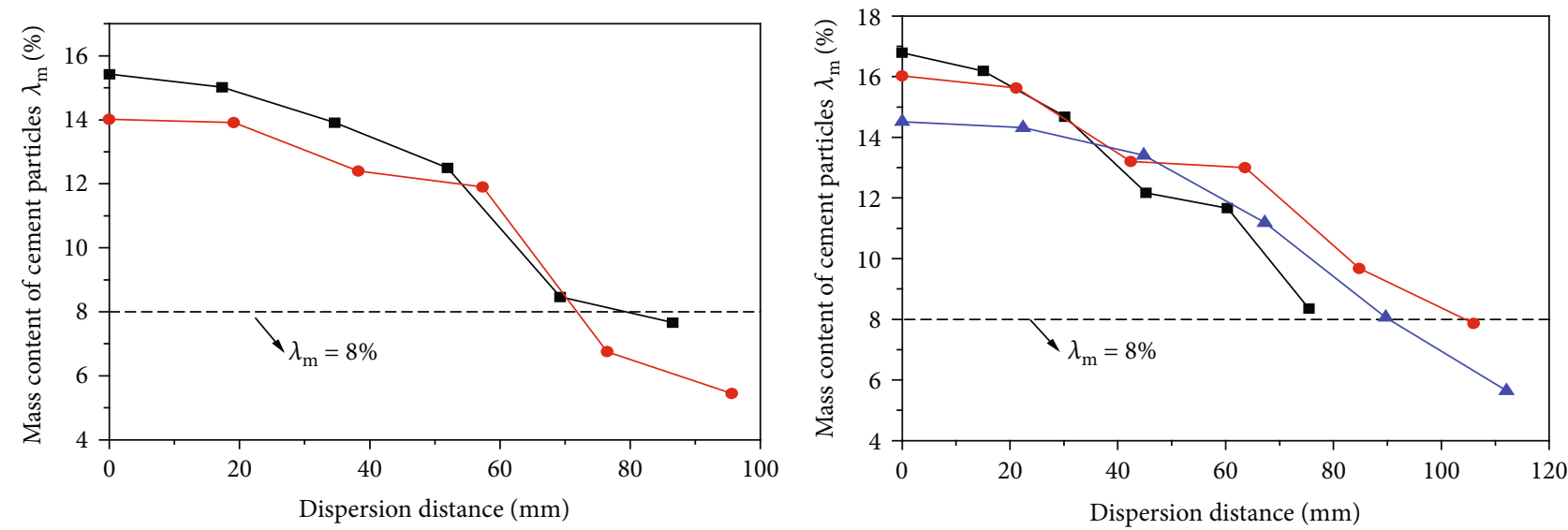

$W / C=1.0$

$W / C=1.2$

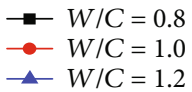

(a)

(b)

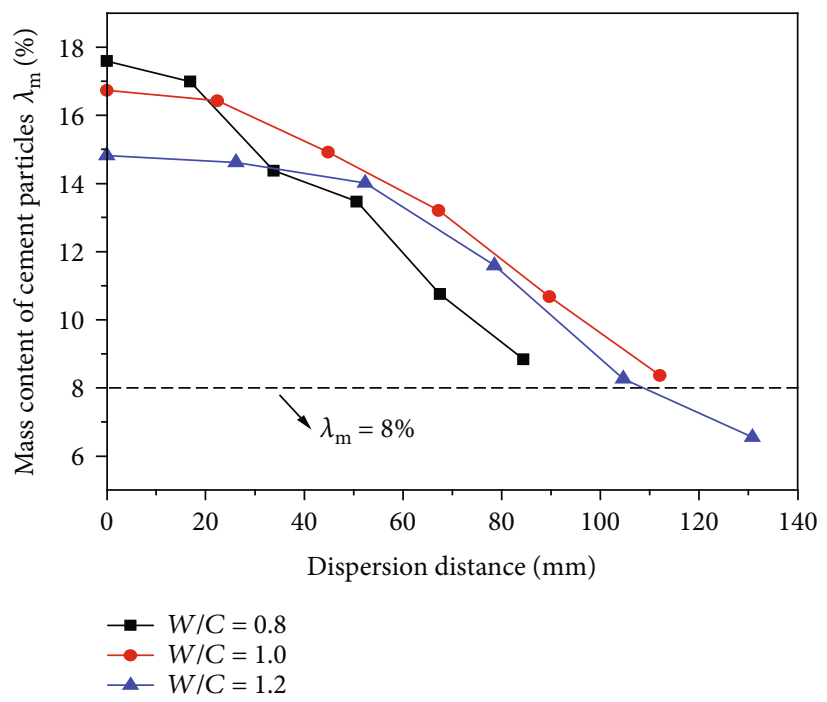

(c)

Figure 6: Distribution of cement content along the radius of grouted mass: (a) $P=180 \mathrm{kPa}$ (b) $P=200 \mathrm{kPa}$ (c) $P=220 \mathrm{kPa}$. 

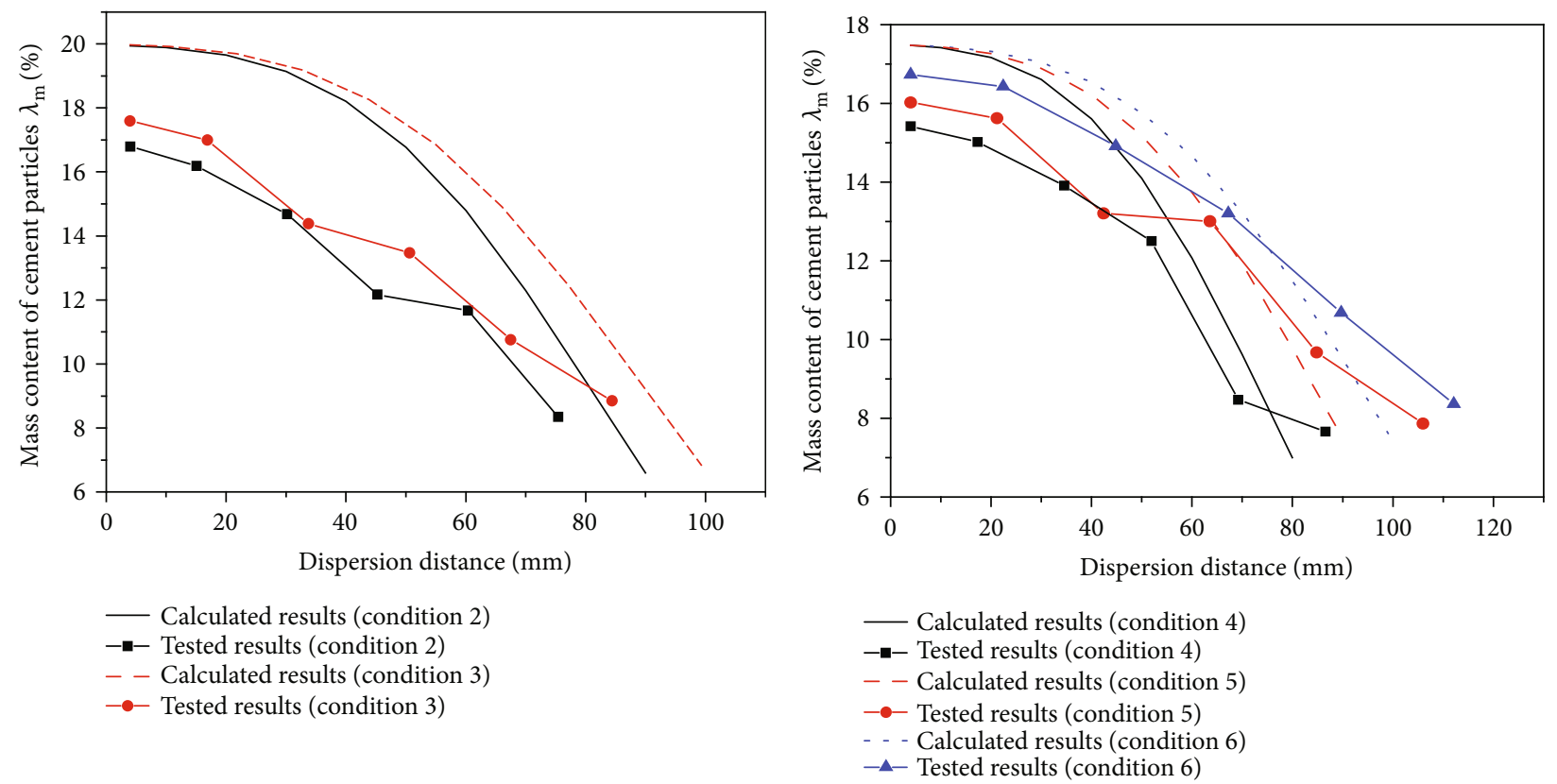

(a)

(b)

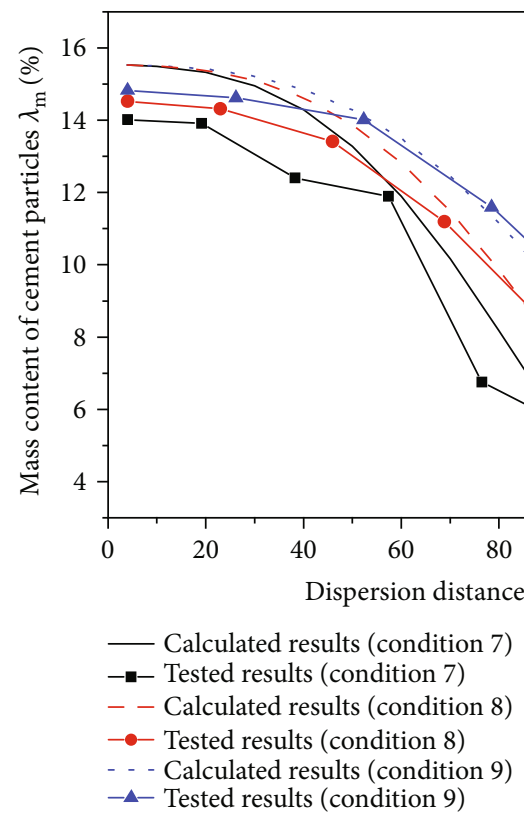

(c)

FIgURE 7: Comparison of the theoretical value and test value of cement particle mass content $\lambda_{\mathrm{m}}$ of grouting mass: (a) $W / C=0.8$; (b) $W /$ $C=1.0 ;(\mathrm{c}) W / C=1.2$.

cement particle mass content $\lambda_{\mathrm{m}}$ in unit volume in the slurry diffusion zone is obtained:

$$
\lambda_{\mathrm{m}}=\frac{\varphi_{\mathrm{c}} \rho_{\mathrm{c}}}{\left(1-n_{0}\right) \rho_{\mathrm{s}}+\varphi_{\mathrm{c}} \rho_{\mathrm{c}}} .
$$

To further validate the consistency between the calculated and experimental results of the cement distribution, the parameters summarized in Table 2 were used in the calculation. Figure 7 shows the comparison between the calculated and experimental results.
As shown in Figure 7, the trend of the calculated and measured distribution of cement along the radial direction reasonably matches with each other. Both the measured and the calculated results demonstrate a reverse-S shape. The calculated cement content is generally larger than the experimental value. The reason for this phenomenon may be attributed to the separation of the grout during the preparation and the set-up of the test so that the concentration of the injected grout may be lower. Therefore, the cement particles may be carried to a farther distance. 
In addition, during the grouting process, the boundary condition may have changed due to the filtration effect. As shown in Figure 7, in the theoretical solution, the boundary condition of the grout concentration at the location of the injector is considered the initial concentration of the grout and is independent of the grouting pressure. However, in reality, it is found out that the higher grouting pressure results in a higher cement content at the core of the cemented sand mass. This result means that the filtration effect may have changed the boundary condition and a higher grouting pressure results in more cement particles retained around the injector. The change of the boundary condition may cause the errors in the theoretical analysis. Figure 7 also shows that the errors decrease with the increase in the water-cement ratio. The reason is not clear but might be attributed to the different boundary conditions caused by the different watercement ratios. Additionally, the cement particles outside the radius of the cemented sand mass may exist, but not high enough to form a cemented mass. Therefore, the cement content outside the cemented sand mass was not tested.

\section{Conclusions}

In this study, grouting tests and EDTA titration tests were conducted in a laboratory to investigate the distribution of the cement content under the filtration effect during grouting. The measured results were compared with the calculated results according to a theoretical equation from an existing study. The following conclusions can be drawn from this study:

(1) Under the filtration effect, the distribution of the cement content in the grouting process demonstrates a reverse "S" shape along the direction of dispersion. For a certain grout, the increase in the grouting pressure would lead to the increase in the cement content and the dispersion distance in the sand layer. Under a certain grouting pressure, the cement particles could transfer farther through the voids of the sand layer if the grout has a higher water-cement ratio. However, the cement content would be lower at the edge of the cemented sand mass, indicating the weak performance in ground improvement

(2) If a cement content of $8 \%$ is taken as the lower limit for ground improvement, the grout with a watercement ratio of 1 has the best performance in terms of the radius of effective ground improvement, followed by the grout with a water-cement ratio of 1.2 and 0.8 . Therefore, in actual engineering practice, an appropriate water-cement ratio of the grout needs to be investigated to satisfy the requirement of strength and range for ground improvement

(3) It is found out that the trend of the calculated cement distribution along the direction of dispersion based on the theoretical equation reasonably matches the measured results. Under the influence of the filtration effect, the concentration of the cement grout at the injector may increase along with the increase in the grouting pressure, inconsistent with the assumption for deriving the theoretical equation. This study proves the overall rationality of the theoretical equation and also reveals the difference between measured and calculated results

(4) The EDTA titration test was introduced in investigating the dispersion of cement grout in dense sand by this study, and the method is proven to be effective

\section{Data Availability}

Some or all data, models, or codes that support the findings of this study are available from the corresponding author upon reasonable request.

\section{Conflicts of Interest}

The authors declare that they have no conflicts of interest.

\section{Acknowledgments}

This study was sponsored by the National Natural Science Foundation of China (Grant Nos. 51678363, 51938008300, and 51809172) and R\&D Projects in Key Areas of Guangdong Province (No. 2019B111108001).

\section{References}

[1] C. Zhu, M. He, M. Karakus, X. Cui, and Z. Tao, "Investigating toppling failure mechanism of anti-dip layered slope due to excavation by physical modelling," Rock Mechanics and Rock Engineering, vol. 53, pp. 5029-5050, 2020.

[2] J. Z. Kuang, Y. W. Zan, and J. Wang, "Theory of grouting in rock and soil medium and engineering project," Science Press, Beijing, 2001.

[3] A. Bezuijen, Compensation Grouting in Sand: Experiment, Field Experiences and Mechanisms, Delft University of Technology, 2010.

[4] Z. Saada, J. Canou, L. Dormieux, J. C. Dupla, and S. Maghous, "Modelling of cement suspension flow in granular porous media," International Journal for Numerical \& Analytical Methods in Geomechanics, vol. 29, no. 7, pp. 691-711, 2005.

[5] A. Bezuijen, M. P. M. Sanders, and D. Den Hamer, "Parameters that influence the pressure filtration characteristics of bentonite grouts," Geotechnique, vol. 59, no. 8, pp. 717-721, 2009.

[6] M. D. Bolton and J. D. Mckinley, "Geotechnical properties of fresh cement grout-pressure filtration and consolidation tests," Geotechnique, vol. 47, no. 2, pp. 347-352, 1997.

[7] M. Eriksson, H. Stille, and J. Andersson, "Numerical calculations for prediction of grout spread with account for filtration and varying aperture," Tunnelling and Underground Space Technology, vol. 15, no. 4, pp. 353-364, 2000.

[8] J. Yoon and C. S. EI Mohtar, "Groutability of granular soils using bentonite grout based on filtration model," Transport in Porous Media, vol. 102, no. 3, pp. 365-385, 2014.

[9] S. Maghous, Z. Saada, L. Dormieux, J. Canou, and J. C. Dupla, "A model for in situ grouting with account for particle filtration," Computers and Geotechnics, vol. 34, no. 3, pp. 164174, 2007. 
[10] O. Chupin, N. Saiyouri, and P. Y. Hicher, "The effects of filtration on the injection of cement-based grouts in sand columns," Transport in Porous Media, vol. 72, no. 2, pp. 227-240, 2008.

[11] J. S. Kim, I. M. Lee, J. H. Jang, and H. Choi, "Groutability of cement-based grout with consideration of viscosity and filtration phenomenon," International Journal for Numerical and Analytical Methods in Geomechanics, vol. 33, no. 16, pp. 1771-1797, 2009.

[12] J. Zhou, K. Fang, and K. Yang, "Bearing capacity of grouted pile considering grout filtration," Proceedings of GeoShanghai 2018 International Conference: Fundamentals of Soil Behaviours. GSIC 2018, A. Zhou, J. Tao, X. Gu, and L. Hu, Eds., , pp. 645-650, Springer, Singapore, 2018.

[13] Z. L. Zhou, H. Z. Zang, S. Y. Wang, X. M. Du, D. Ma, and J. Zhang, "Filtration behaviour of cement-based grout in porous media," Transport in Porous Media, vol. 125, no. 3, pp. 435-463, 2018.

[14] J. Yang, Z. Y. Yin, F. Laouafa, and P. Y. Hicher, "Modeling coupled erosion and filtration of fine particles in granular media," Acta Geotechnica, vol. 14, no. 6, pp. 1615-1627, 2019.

[15] C. Zhu, X. Xu, W. Liu et al., "Softening damage analysis of gypsum rock with water immersion time based on laboratory experiment," IEEE Access, vol. 7, pp. 125575-125585, 2019.

[16] Q. Meng, H. Wang, M. Cai, W. Xu, X. Zhuang, and T. Rabczuk, "Three-dimensional mesoscale computational modeling of soil-rock mixtures with concave particles," Engineering Geology, vol. 277, article 105802, 2020.

[17] S. Akbulut and A. Saglamer, "Estimating the groutability of granular soils: a new approach," Tunnelling and Underground Space Technology, vol. 17, no. 4, pp. 371-380, 2002.

[18] Z. Saada, J. Canou, L. Dormieux, and J. C. Dupla, "Evaluation of elementary filtration properties of a cement grout injected in a sand," Canadian Geotechnical Journal, vol. 43, no. 12, pp. 1273-1289, 2006. 